\title{
A crítica econômica e psicanalítica da homossexualidade na Revolução molecular de Félix Guattari
}

\author{
Economic and psychoanalytical criticism of homosexuality in \\ Félix Guattari's Molecular Revolution
}

\author{
Rondnelly Nunes de Assis \\ Graduação em andamento em Filosofia (2016). Faculdade Jesuíta de Filosofia e Teologia - FAJE. \\ Departamento de Filosofia. Belo Horizonte, MG - Brasil.
}

\begin{abstract}
Resumo: Este trabalho busca esclarecer a noção de homossexualidade na obra Revolução molecular (1985) escrita por Félix Guattari, suas transversalidades e linhas de fuga em relação à manipulação da economia desejante perante o capitalismo. Será abordada a noção de "molecularidade", aqui compreendida como um movimento que visa a uma leitura menor, minoritária, tendo em vista a emergência de focos de resistência em contraposição à lógica dominante das subjetividades capitalísticas. Propomos, pela da leitura da obra, fundamentar as críticas estabelecidas do ponto de vista do homossexual, através da transversalité proposta por Deleuze e Guattari, à lógica dominante na psicanálise e à economia capitalista. Será exposto de que modo o discurso científico é capaz de solidificar concepções de desejo face a uma realidade produtiva, interessada em ampliar a lógica capitalista ao nível da subjetividade em detrimento da singularidade e liberdade dos fluxos desejantes.

Palavras-chave: homossexualidade; psicanálise; economia.
\end{abstract}

Abstract: This works aims to clarify the concept of homosexuality in the book Molecular Revolution (1985) written by Félix Guattari, its transversalities and the lines of flight regarding the management of desiring economy carried out by capitalism. The concept of "molecularity" will be approached as a movement that seeks to cover a minor reading, taking into account the emergence of foci of resistance as opposed to the dominant logic of capitalist subjectivities. We propose, based on the reading of the book, to substantiate the criticisms established from the point of view of the homosexual, through the transversalité proposed by Deleuze and Guattari, to the dominant logic in psychoanalysis and the capitalist economy. It will be exposed in what way the scientific discourse is capable of solidifying conceptions of desire against a productive reality, interested in expanding the capitalist logic to the subjectivity level in the detriment of the singularity and freedom of the libidinal flows.

Keywords: homosexuality; psychoanalysis; economy. 


\section{INTRODUÇÃO}

É importante, de início, contextualizar o leitor sobre as circunstâncias que levaram à escrita do texto que será analisado; a homossexualidade na França, ainda na década de 70, era criminalizada - mesmo após as insurgências de Maio de 68, exemplificadas por autores como Gilles Deleuze e Guattari, com seu Anti-Édipo (1972), e Guy Debord, inclusive dentro dos próprios movimentos militantes, o que levaria ao surgimento de grupos de ação feministas e homossexuais, em clara oposição à tendência dominadora masculina e heterossexual dentro do contexto político. É importante também notar o papel da luta antipsiquiátrica nesse contexto, levando em conta as contribuições de Michel Foucault para o método de Guattari, que ativamente produziu conhecimento e experiências a partir da marginalidade da loucura e seus desdobramentos. Esse tipo de atividade evidentemente leva a uma reflexão diferenciada, dada a mudança de perspectiva a partir da qual será traçada a crítica e a posição, e é nesse estilo minoritário de pensamento e agir político que a Revolução molecular (1985) está inserida.

O cenário cultural francês, em oposição à realidade cada vez mais repressora por parte do Estado, é levado a uma efervescência intelectual marcadamente na área das humanidades, tendo como efeito o surgimento de uma intelligentsia minoritária capaz de dar conta das questões particulares de sua época, superando os chavões tradicionais da filosofia da esquerda (como a rejeição, à época da revolução russa, da homossexualidade), que relega aos temas relativos à sexualidade não produtiva uma valoração negativa, como se não fossem filosoficamente relevantes.

É essa a condição de possibilidade do trabalho de autores como Jean Genet, no teatro, e Guy Hocquenghem na filosofia - sendo a obra do último de valor incomparável se tratando de estudos sobre a homossexualidade; sua obra Le désir homosexuel (1972, sem tradução para o português) versa sobre as diversas concepções históricas e científicas sobre a homossexualidade, aliando o método filosófico à psicanálise para, a partir daí, poder esvaziar essas áreas de suas pressuposições e abrir caminho para um pensamento além dos truísmos totalizantes da ciência psicológica desde o início dos estudos da sexualidade humana, como se pode observar na afirmação de Deleuze:

Nós nos dirigimos àqueles que acham que toda essa história de Édipo, castração, pulsão de morte [...] etc. é bem monótona, e triste, um romrom. Nós nos dirigimos aos inconscientes que protestam. Buscamos aliados. Precisamos de aliados. (DELEUZE, 1992, p. 34)

Associada a essa conjuntura, ocorre também uma apropriação militante do método psicanalítico, o que permitiria sua reestruturação, dada a situação em que ela se encontrava. É buscada uma saída à triangulação edipiana proposta por Freud, que marcou significativamente o pensamento da sexualidade humana, uma vez que ela traz consigo elementos faltantes, desejos nunca realizáveis, a repressão como necessidade fundamental no desenvolvimento da pessoalidade e, mais adiante, da própria sexualidade. Sobre esse ponto, segundo o autor, a psicanálise:

[...] quis domar desde o início o desejo. O inconsciente lhe apareceu como algo bestial, perigoso. As sucessivas formulações de Freud nunca se afastaram desta posição. A energia libidinal deve converter-se no sistema maniqueísta dos valores dominantes, ela deve investir as representações formais. Nada de ter prazer fazendo cocô na cama sem desencadear um investimento culposo! (GUATTARI, 1985, p. 30)

A partir disso, é levada a termo a tarefa de desedipianizar a psicanálise, ou seja, de libertá-la das categorias da falta, da lacuna e da repressão na qual ela está inserida 
enquanto mecanismo de sustentação. A partir daí Guattari trata de pensar a psicanálise institucional como uma força utilizada de forma repressora, uma vez que sofre de uma esclerose conformista (p. 166) - ainda mais no seu desdobramento lacaniano, na França, "muito mais despótico, do ponto de vista da teoria e da instituição" (p. 133). Assim, é assumida a tarefa de reelaborar a psicanálise teoricamente e mostrar de que forma é possível libertar o desejo e o corpo das sujeições econômicas das ciências duras.

\section{O DEVIR MINORITÁRIO}

A marginalidade é o lugar onde se podem ler os pontos de ruptura nas estruturas sociais e os esboços de problemática nova no campo da economia desejante coletiva. Trata-se de analisar a marginalidade, não como uma manifestação psicopatológica, mas como a parte mais viva, a mais móvel das coletividades humanas nas suas tentativas de encontrar respostas às mudanças nas estruturas sociais e materiais. (GUATTARI, 1985, p. 46)

A minoria, por definição, possui um caráter estritamente relativo, pois se revela uma fuga a partir da oposição a alguma norma - estatística, moral, sexual - dominante; ela, por assim dizer, não se caracteriza como revolucionária de forma alguma, já que é possível falar de homossexualidades conservadoras, perversas e que sustentam o poder falocrático (compreende-se aqui uma referência ao falo freudiano enquanto o que funda a dominação e o poder masculino, p. 34). Há, por exemplo, aqueles homossexuais que se escondem - à época da publicação da Revolução Molecular, identificados pelo autor como homens de letras, de negócios, etc. --, sustentando assim a repressão sexual da sociedade dominante. Esse tipo é sustentado pelas categorias da psicanálise - perversão, fixação pré-genital -, o que supostamente desloca a regulação da repressão sexual do campo da moralidade para o da ciência.

Há, entretanto, outra categoria: a do homossexual mais vanguardista, ligado ao devir-mulher, que levanta certos questionamentos; primeiro: esse personagem, exemplificado como um homossexual "mais minoritário" - como os militantes da FHAR $^{1}$ - tece uma oposição muito direta não apenas à sexualidade heterossexual dominante e suas categorias psicanalíticas e morais de repressão, mas também aos tipos "reprimidos" de sexualidades, se opondo às dinâmicas de poder próprias à interiorização da homossexualidade, tanto institucional quanto moralmente, e trabalha pelo reconhecimento, mas mantendo-se ainda as divisões.

Uma terceira categoria, chamada molecular, trata do ponto de convergência entre vários devires minoritários - homossexuais, travestis, psicóticos, drogados, prostitutas, mulheres, etc. (GUATTARI, 1985, p. 35); nesse nível molecular, o que ocorre é uma aproximação mais radical do devir mulher - já que aqui, tendo como referência não uma identidade ou categoria fixa, mas um "denominador comum", onde as barreiras entre os corpos e subjetividades estão mais borradas, permitindo que se superem as barreiras entre os gêneros, não buscando uma unicidade entre os divergentes, mas sim o ponto de passagem entre eles.

Diz-se de sua proximidade com o devir mulher já que "[...] as mulheres são os únicos depositários autorizados do devir corpo sexuado. Um homem que se desliga das disputas fálicas, inerentes a todas as formações de poder, se engajará, segundo diversas modalidades possíveis, num tal devir mulher" (GUATTARI, 1985, p. 35). Dessa forma, todo engajamento dissidente da libido deve devir corpo feminino,

\footnotetext{
${ }^{1}$ Frente Homossexual de Ação Revolucionária, grupo de homossexuais militantes muito ativos na década de 70, frequentemente presente na obra de Guattari e responsáveis pela disseminação do pensamento homossexual militante.
} 
como linha de fuga, já que até mesmo as formas da marginalidade são pensadas como válvulas de segurança; da mesma forma que o homossexual, toda sexualidade psicótica, infantil, sadomasoquista, travesti, etc. compartilha desse mesmo devir - a dissidência da sexualidade passa, necessariamente, por ele.

Deve-se, entretanto, evitar cair na armadilha de equiparar o devir à figura social da mulher, pois ela existe apenas no campo social que a define - enquanto relação de poder; o devir feminino, por sua vez, é uma "linha de fuga do socius repressivo, como acesso possível a um 'mínimo' de devir sexuado" (GUATTARI, 1985, p. 36). Tratamos, aqui, de uma semiotização, ou seja, de uma forma de subjetivação oposta à dominante, masculina, heterossexual. Não quer dizer que toda mulher seja homossexual, ou que todo psicótico seja criança - mas todos esses sujeitos, do ponto de vista de sua ruptura com as normas dominantes, compartilham um devir marginal, aqui tratado como feminino. Diz o autor:

A oposição homem/mulher serve para fundar a ordem social, antes das oposições de classe, de casta, etc. Inversamente, tudo o que quebra as normas, tudo o que rompe com a ordem estabelecida, tem algo a ver com o homossexualismo ${ }^{2}$ ou com um devir animal, um devir mulher, etc. Toda semiotização em ruptura implica numa sexualização em ruptura. Não se deve, portanto, a meu ver, colocar a questão dos escritores homossexuais, mas sim procurar o que há de homossexual em um grande escritor, mesmo que ele seja, além disso, heterossexual. (GUATTARI, 1985, p. 36)

\section{PERSPECTIVISMO HOMOSSEXUAL, TRANSVERSALIDADE E CONTESTAÇÃO}

A partir dessa perspectiva, que trata do desvio da subjetivação heterossexual masculina dominante, em que todos seus desvios passam por uma semiotização outra, potencialmente molecular, à parte das idealizações binárias das oposições sobre as quais são fundadas as diferenças, os desejos e identidades, o autor trata da questão dos devires como distintos dos objetos dos quais eles derivam seus nomes; é isso que permite, por exemplo, que se fale de um devir animal na obra de Kafka. Gregor Samsa, de sua obra A Metamorfose (1997), reterritorializa-se no devir-animal; este, por sua vez, pressupõe sempre um bando, uma matilha. Não se trata de pensar que o humano que devém animal é solitário - pelo contrário, ele se encontra em matilhas e, a partir daí, coletivamente lutam pela vida: "Num devir-animal, estamos sempre lidando com uma matilha, um bando, uma população, um povoamento, em suma, com uma multiplicidade" (DELEUZE; GUATTARI, 1997, p. 20).

Esse comportamento de matilha, no qual organizações moleculares, ao devirem animais, se organizam em torno de um propósito seria abordado mais tarde por Antonio Negri e Michael Hardt em sua obra Multidão (2005):

Quando uma rede disseminada ataca, investe sobre o inimigo como um enxame: inúmeras forças independentes parecem atacar de todas as direções num ponto específico, voltando em seguida a desaparecer no ambiente. (NEGRI; HARDT, 2005, p. 130)

Dessa forma, seria possível pensar o específico agenciamento homossexual molecular descrito por Guattari a partir da transversalidade, como proposta por Deleuze e Guattari (1995), que primeiro trata de abandonarmos o paradigma arborescente, ou seja, hierárquica, linear, ora puramente vertical, ora puramente horizontal. Dessa perspectiva, defrontamo-nos com a transversalidade e o rizoma. Este nos permite

\footnotetext{
${ }^{2}$ As referências ao "homossexualismo" serão mantidas por conta da linguagem utilizada à época; nesse caso, não possuem conotações pejorativas.
} 
compreender as estratificações sociais de forma tanto horizontal quanto vertical, observando seu movimento transversalmente-ou seja, compreendendo os diferentes momentos e devires em jogo em um dado agenciamento; é isso que nos permite, por exemplo, a reflexão filosófica na literatura, tratando personagens como filósofos, ou o oposto; permite também que compreendamos a homossexualidade nas pessoas, nos animais e na natureza. Essa transversalidade leva-nos à possibilidade da reflexão não-localizada, nem estritamente social, nem estritamente sexual; permite-nos compreender o fenômeno com a complexidade com que ele se dá: permitindo compreender a produção da diferença e da mesmidão, seus contatos íntimos e a fuga ou o desejo em relação ao outro:

[...] o rizoma conecta um ponto qualquer com outro ponto qualquer e cada um de seus traços não remete necessariamente a traços da mesma natureza; ele põe em jogo regimes de signos muito diferentes, inclusive estados de não-signos. O rizoma não se deixa conduzir nem ao Uno nem ao múltiplo. Ele não é o Uno que se torna dois, nem mesmo que se tornaria diferente três, quatro ou cinco etc. Ele não é feito de unidades, mas de dimensões, ou antes de direções movediças. Ele não tem começo nem fim, mas sempre um meio pelo qual ele cresce e transborda. (DELEUZE; GUATTARI, 1995, p. 32)

Assim, a partir do conceito de rizoma, fica mais clara a perspectiva de Guattari sobre certos agentes sociais capazes de trazer a contestação a um panorama mais concreto e militante.

Não mais tratando de territórios de agrupamento de iguais nem estritamente de diferentes, surge a possibilidade de uma contestação imanente: os próprios excluídos, à guisa de problematizar os agenciamentos dominantes dos quais tentam fugir e criar, coletivamente, outros (a matilha, abordada anteriormente, característica do devir animal), se opõem a eles ao invés de buscar reformá-los:

A questão fica desse modo deslocada: os homossexuais, homens e mulheres, recusam o estatuto de minoria oprimida e pretendem levar uma ofensiva política contra a servidão de todas as formas de sexualidade aos sistemas de reprodução e aos valores das sociedades capitalistas e socialistas burocráticas. Trata-se, de fato, mais de transexualidade do que de homossexualidade: trata-se de definir o que seria a sexualidade numa sociedade libertada da exploração capitalista e das relações de sujeição que ela desenvolve em todos os níveis da organização social. Deste ponto de vista, a luta pela liberdade do homossexualismo torna-se parte integrante das lutas de libertação social. (GUATTARI, 1985, p. 41)

A partir das observações anteriores sobre o devir-mulher enquanto condição de possibilidade de qualquer desvio da norma heterossexual, e também da transversalidade que emerge a partir desse contato pela diferença e pelo escárnio, é possível compreender de que forma uma contestação social, política, sexual e econômica poderia emergir de sujeitos tão à margem das normas desse mesmo sistema que buscam problematizar. A questão, à primeira vista absurda, de como um homossexual pode criticar a norma heterossexual dominante agora se faz mais clara: a própria exclusão coloca o sujeito à margem, devindo animal, matilha, agrupando-se a outros diferentes - inclusive de si mesmo - e construindo e explorando linhas de fuga.

\section{CONCLUSÃO}

Uma análise genealógica da sexualidade nos mostra como a ciência, a moral religiosa e outros fatores foram construindo um saber normativo acerca do prazer. Num momento em que esses saberes estão ruindo e que estes sujeitos, agora não mais patológicos, se veem envolvidos em movimento de contestação política - como os maoístas franceses, na década de 60 -, é apenas uma questão de tempo para que estes surjam mais potentes, menos patológicos e edipianizados. 
Não se trata de uma afirmação de que todo homossexual é revolucionário, ou que se deve ser homossexual para revolucionar; o ponto é a ruptura com a economia libidinal dominante, aqui posta a serviço do capitalismo como meio de controle social e político. Não há possibilidade de se negar o funcionalismo da família heterossexual tradicional à manutenção e reprodução de sujeitos neuróticos e produtivos capitalisticamente; também não é possível negar que a psicanálise, como se constitui a partir de seu cerne freudiano, apenas contribui para a edipianização e a patologização de uma característica aqui tida como inerentemente contestadora das normas dominantes. A patologia de sexualidades dominantes deve ser vista como um sintoma da própria contestação; ninguém precisa ouvir os loucos, e estes devem ser encarcerados. Aqui, porém, não vemos mais o movimento de encarceramento, mas sim uma marginalidade voluntária: a formação espontânea de guetos, milícias e matilhas. Não há mais a necessidade de ser aceito, ou de compartilhar valores com o grupo dominante, mas sim de formar grupos na diferença a partir desse devir transversal comum que coloca à margem os sujeitos que não compactuam ou suportam a normatização do desejo.

A problemática não se esgota nessa identificação do devir contestatório com sujeitos concretos, nem com a homossexualidade sendo posta como centro da crítica econômica e social proposta pelo autor. Trata-se, na verdade, de um diagnóstico das linhas de fuga e contestação imanentes ao tecido social que, de toda forma, o leva para além de si mesmo, buscando novas possibilidades de fugir à norma dominante, à sexualidade genitalizada, ao corpo marcado e posto a serviço da reprodução do capital libidinal e econômico.

Analisar o menor, o molecular, permite que identifiquemos as potências em jogo num dado momento; o rizoma nos dá o panorama dessa relação: não se trata de um contra o outro, mas de um jogo de forças, em atração e repulsão, identificação e desidentificação, que se exprime no tecido social.

O menor não significa aquele que é inferior, menos importante, insignificante, mas diz respeito à prática realizada por uma minoria que assume sua marginalidade em relação às práticas representativas majoritárias, buscando como estrangeiro dentro de uma língua maior, a atividade de uma língua menor. (SILVA, 2016, p. 17)

É a partir da conjectura França, onde o próprio Félix Guattari se envolvia tanto nos movimentos militantes quanto acadêmicos, que ele tece suas teses acerca da homossexualidade, da loucura, etc., muitas vezes junto a Gilles Deleuze. O próprio Guattari, autoidentificado como homossexual molecular (percebe-se, aqui, o próprio movimento da transversalidade e dos devires), foi reprimido por sua atividade na intelligentsia militante abordada anteriormente; seu texto Três milhões de perversos no banco dos réus (p. 38) é uma resposta à acusação de "atentado ao pudor" em março de 73 por sua atuação como diretor da publicação do número 12 do periódico Recherches, intitulado Trois milliards de pervers: Grande encyclopédie des homosexualités ${ }^{3}$. Em suas próprias palavras,

[...] a acusação de pornografia é apenas um pretexto, fácil de invocar neste domínio particular; o essencial é reprimir "para servir de exemplo" [...] Quisemos, assim, dar diretamente a palavra aos homossexuais. E o que aconteceu? Reprovaram nossa inconveniência. Mas de que natureza é esta inconveniência, se não política? (GUATTARI, 1985, p. 41)

Fazendo referência à utilidade política da repressão sofrida por ele e pelos autores dos textos desse volume - dentre eles, diversos pensadores ligados à matilha da contestação homossexual da época -, faz-se mister pensar no progresso no pensamento da questão homossexual não apenas na França, mas também em todo o mundo; não se trata da discussão pelos direitos, ou da assimilação do homossexual na sociedade

\footnotetext{
${ }^{3}$ Republicado recentemente pelas Editions Acratie (2005), na França.
} 
dita normal, mas do pensamento nômade de uma matilha surgido espontaneamente no seio de uma sociedade repressiva.

No Brasil, por exemplo, vemos emergir literalmente uma língua menor entre os homossexuais, além de toda uma tradição poética, que à guisa da sobrevivência, vem se tornando cada vez mais uma ferramenta discursiva publicitária, sofrendo uma territorialização molar. Não é para a eternidade que os grupelhos se formam: eles têm validade, e inclusive são muito efêmeros; a questão que se põe é a da eternidade da resistência, da intensidade da oposição e da crítica, diretamente proporcional à força bruta com que se normaliza e patologiza.

Sendo assim, o pensamento nômade exposto por Félix Guattari em sua Revolução Molecular proporciona-nos ferramentas de análises que extrapolam sua realidade francesa; esse pensamento é de extrema atualidade, visto que é perfeitamente possível transpor a outros cenários as teses desenvolvidas pelo autor.

Guattari, então, responde aos "surdos" molares, aos repressores acadêmicos, economistas, neuróticos em geral que assumem a função de intelectuais orgânicos que buscam, por fim, manter tudo como está - o prazer limitado, o desejo genitalizado e as hierarquias e estruturas sociais, no máximo, levemente deslocados; os supostos normais que tratam a homossexualidade como patologia - pedofilia, zoofilia - sem ao menos perceberem o que eles têm, molecularmente, de homossexual, e o porquê de tão ferrenha oposição, se eles supostamente nada têm a ver com isso:

Lembrete para os surdos: a bicha, não mais do que o esquizo, não é um revolucionário em si, o revolucionário dos novos tempos! Dizemos, apenas, que entre alguns outros, ele pode ser, ele pode vir a ser o lugar de uma ruptura libidinal maior na sociedade, um dos pontos de emergência da energia revolucionária desejante, da qual o militantismo clássico permanece desconectado. Nem por isso perdemos de vista que existe também uma loucura de asilo infinitamente infeliz, ou um homossexualismo edípico infinitamente envergonhado e miserável! E, no entanto, convém ficar à escuta inclusive destes casos de extrema repressão. (GUATTARI, 1985, p. 39)

Correspondência: Rondnelly Nunes de Assis. Faculdade Jesuita de Filosofia e Teologia - FAJE. Departamento de Filosofia. Av. Dr. Cristiano Guimarães, 2127. Planalto. Belo Horizonte - MG - Brasil. CEP: 31720-300. E-mail: rond.nunes@gmail.com.

Apoio financeiro: Nenhum.

Conflito de interesses: Nenhum

Todos os autores leram e aprovam a versão final submetida à revista Em curso. 


\section{Referências}

DELEUZE, G.; GUATTARI, F. Kafka: por uma literatura menor. Rio de Janeiro: Imago, 1977. Mil Platôs. São Paulo: Editora 34, 1995.

Mil Platôs 4. São Paulo: Editora 34, 1997.

DELEUZE, G. Conversações. São Paulo: Editora 34, 1992.

GUATTARI, F. Revolução Molecular: pulsações políticas do desejo. São Paulo: Brasiliense, 1985.

HARDT, M.; NEGRI, A. Multidão. São Paulo: Record, 2005.

KAFKA, F. A Metamorfose. São Paulo: Companhia das Letras, 1997.

SILVA, M. V. Kafka, Deleuze e a literatura menor em A Metamorfose e no Processo. 2016. Dissertação (Mestrado em Letras) - Pontifícia Universidade Católica de Goiás, Goiânia.

Recebido em: 19/Abr/2018 - Aceito em: 20/Set/2018. 